\title{
Screening for congenital heart disease in a Singapore neonatal unit
}

\author{
Alvin Jia-Hao $\underline{N g e o w}^{1}$, MMed (Paeds), FAMS, Mary Grace $\underline{T a n}^{1}$, MD, DN, Jonathan Tze-Liang $\underline{C h o o}^{2}$, FRCPCH, MPH, \\ Teng-Hong $\underline{T a n}^{2}$, MMed, FRCPCH, Wei Ching $\underline{T a n}^{3}$, MRCOG, FAMS, Daisy Kwai-Lin Chan ${ }^{1}$, MMed (Paeds), FAMS
}

INTRODUCTION Congenital heart disease (CHD) is a leading cause of infant mortality. The aim of this study was to evaluate the efficacy of a neonatal screening programme for CHD before the introduction of pulse oximetry.

METHODS This was a retrospective review of live births in the period 2003-2012. Cases of CHD were detected through prenatal ultrasonography and/or postnatal examination, and confirmed using two-dimensional echocardiography. Data was rigorously checked against multiple sources. The antenatal detection rate, sensitivity, specificity, predictive values and likelihood ratios of the screening programme were analysed for all cases of CHD and critical CHD.

RESULTS The incidence of CHD was 9.7 per 1,000 live births. The commonest CHD was ventricular septal defect (54.8\%). The antenatal detection rate was three times higher in the critical CHD group (64.0\%) compared to the group as a whole (21.1\%). The sensitivity and specificity of screening was $64.5 \%$ and $99.7 \%$ for all CHD, and $92.9 \%$ and $99.1 \%$ for the critical CHD group, respectively. The positive likelihood ratio was 215 and 103, while the negative likelihood ratio was 0.36 and 0.07 for all CHD and critical CHD, respectively.

CONCLUSION The CHD screening programme had excellent specificity but limited sensitivity. The high positive likelihood ratios indicate that where sufficient risk factors for CHD are present, a positive result effectively confirms the presence of $\mathrm{CHD}$. The low negative likelihood ratio for critical CHD indicates that, where prior suspicion for critical $\mathrm{CHD}$ is low, a negative result is reassuring.

Keywords: critical congenital cardiac defect, neonatal screening, prenatal ultrasonography, sensitivity, specificity

\section{INTRODUCTION}

Congenital heart disease (CHD) is a leading cause of infant mortality, accounting for over $40 \%$ of deaths from congenital defects ${ }^{(1)}$ and $4.2 \%$ of deaths in infancy. ${ }^{(2)}$ Advances in prenatal ultrasonography have enabled CHD to be visualised during the second and third trimesters, allowing fetal intervention, ${ }^{(3)}$ postnatal stabilisation and definitive surgery or trans-catheter intervention to be carried out early. ${ }^{(4)}$ When undetected or detected late, the neonate with severe CHD is at risk of circulatory collapse, shock and metabolic acidosis. Poor preoperative clinical status is known to be associated with increased mortality. ${ }^{(5,6)}$ Timely diagnosis of CHD is, therefore, important for improved outcomes, ${ }^{(7,8)}$ yet a significant proportion of $\mathrm{CHD}$ may not be detected through prenatal screening and postnatal examination alone. ${ }^{(9-11)}$ In 2009, pulse oximetry was introduced in some countries as part of neonatal screening to detect conditions associated with desaturation, such as cyanotic heart disease and persistent pulmonary hypertension of the newborn. ${ }^{(12)}$ While some local hospitals have incorporated pulse oximetry screening for the newly born, its sensitivity and specificity for detection of cyanotic heart diseases are unknown. ${ }^{(13)}$

The objective of this study was to determine the incidence and range of $\mathrm{CHD}$ among newly born babies at Singapore General Hospital (SGH), and evaluate the efficacy of a neonatal screening programme comprising prenatal ultrasonography and postnatal clinical examination for CHD diagnosed through echocardiography.

\section{METHODS}

This was a retrospective study of live births between January 2003 and December 2012 conducted at SGH, a tertiary care teaching institution. Pregnant women who were booked for antenatal care underwent first trimester ultrasonography for dating, confirmation of fetal viability and risk assessment for aneuploidy. Detailed imaging of fetal anatomy was performed at 18-20 weeks of gestation, followed by routine growth imaging at 30-34 weeks of gestation. For ultrasonography, we routinely used the fourchamber view, three-vessel view, septal view, views of right/left ventricular outflow tracts, and views of the ductal and aortic arch to diagnose CHD prenatally. Prenatal imaging was performed using the Acuson 128Xp/10 (Siemens Medical Solutions, Malvern, PA, USA), and images were stored in a database maintained at the Prenatal Diagnostic Centre, SGH. When a fetal cardiac anomaly was detected, the mother was counselled by maternalfetal specialists. Selected cases of fetal CHD were referred to the paediatric cardiology unit of KK Women's and Children's Hospital $(\mathrm{KKH})$ for fetal echocardiographic confirmation, and those associated with significant risk of mortality were offered pregnancy termination. Parents of fetuses with critical CHD that underwent termination or suffered intrauterine death were routinely offered postmortem examination with consent.

${ }^{1}$ Department of Neonatal and Developmental Medicine, Singapore General Hospital, ${ }^{2}$ Cardiology Service, Department of Paediatric Subspecialties, KK Women's and Children's Hospital, ${ }^{3}$ Department of Obstetrics and Gynaecology, Singapore General Hospital, Singapore

Correspondence: Dr Alvin Jia-Hao Ngeow, Consultant, Department of Neonatal and Developmental Medicine, Singapore General Hospital, Level 3 Academia, 20 College Road, Singapore 169856. Alvin.Ngeow.J.H@singhealth.com.sg 
In the first 24 hours of life, all live-born neonates routinely underwent detailed clinical screening by an attending neonatologist. During the study period (2003-2012), there was no unit policy of routine pulse oximetry screening. Babies who were diagnosed with CHD were included in the study, but those with arrhythmia, isolated patent ductus arteriosus, isolated patent foramen ovale, persistent pulmonary hypertension of the newborn and pericardial effusion were excluded. Diagnosis of $\mathrm{CHD}$ was made on the basis of two-dimensional echocardiography performed by $\mathrm{KKH}$ paediatric cardiologists, who held visiting specialist rights to $\mathrm{SGH}$ as part of the SingHealth cluster. Echocardiography was performed in accordance with standard techniques using the GE Vivid S5 (General Electric, Boston, MA, USA). Details of the cases were stored in an electronic $\mathrm{KKH}$ cardiology database.

All cases of $\mathrm{CHD}$ were verified through counter-checking against multiple sources. Firstly, a list was compiled from the SGH Birth Defect Registry, which had been carefully maintained over the years by neonatologists. Secondly, we reviewed the hard copy echocardiography records of those who had been referred with cardiac symptoms but proven on echocardiography to have structurally normal hearts (false positives). Thirdly, KKH's cardiology database was checked for cases that were discharged as apparent well babies from SGH but diagnosed later at KKH with CHD (i.e. false negatives), either as inpatients or outpatients. We checked the KKH cardiology database for records up to December 2014, presuming that those born up to 2012 (i.e. end of the study period) would have become symptomatic by 2014 . Data was rigorously cross-checked to ensure completeness and to avoid double-counting. Finally, we checked the SGH Prenatal Diagnostic Centre database for mothers who opted for pregnancy termination or experienced intrauterine death following prenatal diagnosis of CHD.

Diagnosis of $\mathrm{CHD}$ was coded according to the International Classification of Diseases Ninth Revision (ICD-9) - British Paediatric Association (BPA) system. ${ }^{(14)}$ Babies with more than one cardiovascular anomaly (e.g. pulmonary atresia and ventricular septal defect) were classified according to the cardiac malformation that was associated with the initial presentation and/or required earlier intervention (pulmonary atresia, in the example above). Data was coded for gestational age, birth weight, gestational size (small, appropriate or large for gestational age based on the growth charts of Fenton et $\mathrm{al}^{\left({ }^{(15)}\right)}$, Apgar scores, antenatal history, family history of CHD, indication for referral, and associated anomaly or syndrome. Statistical analysis was performed using SPSS Statistics version 17.0 for Windows (SPSS Inc, Chicago, IL, USA). Ethical approval was granted by the SingHealth Centralised Institutional Review Board E (CIRB Reference: 2013/124/E).

Apart from analysing all types of $\mathrm{CHD}$, a subanalysis was carried out for seven selected 'critical CHD', which was known to be associated with haemodynamic decompensation. ${ }^{(16)}$ The seven critical CHDs included (in alphabetical order): atrioventricular septal defect (code 745.69); coarctation of the aorta (code 747.10); hypoplastic left heart syndrome (code 746.70); pulmonary atresia (code 746.01); tetralogy of Fallot (code 745.20); total anomalous pulmonary venous drainage (TAPVD; code 747.41); and transposition of the great arteries (code 745.10). ${ }^{(16)}$

The antenatal detection rate was defined as the proportion of mothers who underwent fetal anomaly imaging and received an accurate diagnosis. The denominator included CHD live births diagnosed through echocardiography (the 'gold standard'), as well as fetuses with CHD who had been terminated or had undergone intrauterine death. Where there was no postnatal echocardiography, obstetric records were examined for postmortem findings. In cases without postmortem examination, fetal echocardiographic findings (performed by the $\mathrm{KKH}$ paediatric cardiology unit) was regarded as diagnostic in lieu of further confirmation.

Data on CHD was analysed for sensitivity, specificity, positive and negative predictive values, and positive and negative likelihood ratios for all CHD, as well as for the seven selected critical CHDs. Sensitivity was defined as the proportion of $\mathrm{CHD}$ babies that were diagnosed before discharge from $\mathrm{SGH}$. Specificity was defined as the proportion of babies without CHD who were assessed as having been well during inpatient stay. Echocardiographic records were unavailable for babies born before 2007. Positive predictive value was the probability that babies with a positive screen truly had CHD. Negative predictive value was the probability that babies with a negative screen truly did not have CHD. A positive likelihood ratio was defined as the likelihood that a positive result on screening would be expected in a patient with CHD as compared to the likelihood that the same result would be expected in a patient without CHD. A negative likelihood ratio was the likelihood that a negative result would be expected in a patient with $\mathrm{CHD}$ as compared to the likelihood that the same result would be expected in a patient without $\mathrm{CHD} .{ }^{(17)}$

\section{RESULTS}

Over the ten-year period from 2003 to 2012, there were 16,059 live births, of which 410 had a cardiac lesion. After excluding 171 cases of isolated patent ductus arteriosus, 80 cases of atrial septal defect/patent foramen ovale, three cases of persistent pulmonary hypertension of the newborn and one case of pericardial effusion secondary to central line extravasation, the remaining 155 cases were analysed (Fig. 1). The incidence of CHD at birth was 9.7 per 1,000 live births (155 out of 16,059). Of these, 108 cases were diagnosed prior to discharge from $\mathrm{SGH}$, while the remaining 47 cases with apparent healthy birth were discovered in the $\mathrm{KKH}$ cardiology database. There was no significant change in the live birth incidence of CHD over the ten-year period (Fig. 2). With two-tailed values and $p<0.05$ as the level of significance using the Z-test for a difference in proportion, the incidence in the first five years was not significantly different from the latter half.

The mean $( \pm$ standard deviation $[\mathrm{SD}])$ gestational age and birth weight of the study population was $36.6 \pm 3.4$ weeks and $2,705 \mathrm{~g} \pm 802 \mathrm{~g}$, respectively. Most (112/155, 72.3\%) of the babies were classified as appropriate for gestational age, while 


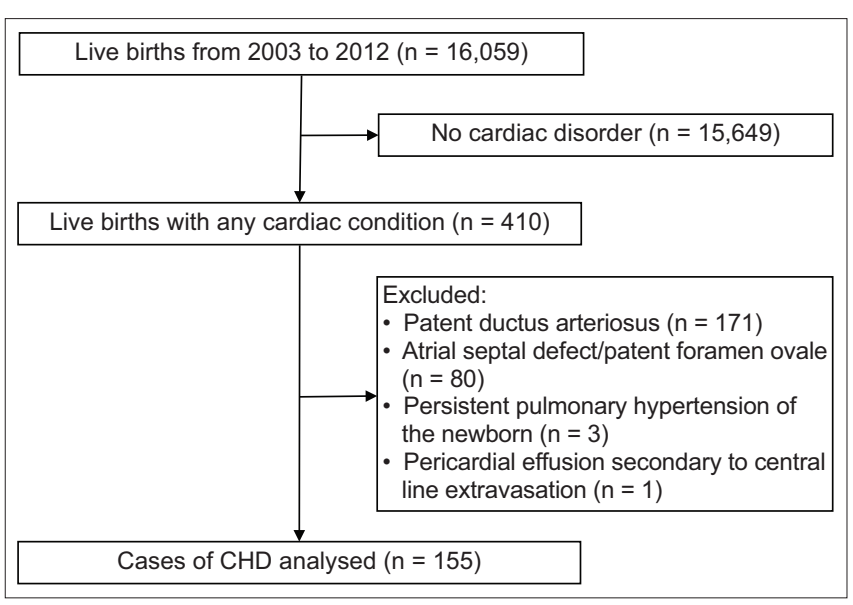

Fig. 1 Flowchart shows the enrolment of study subjects with congenital heart disease (CHD).

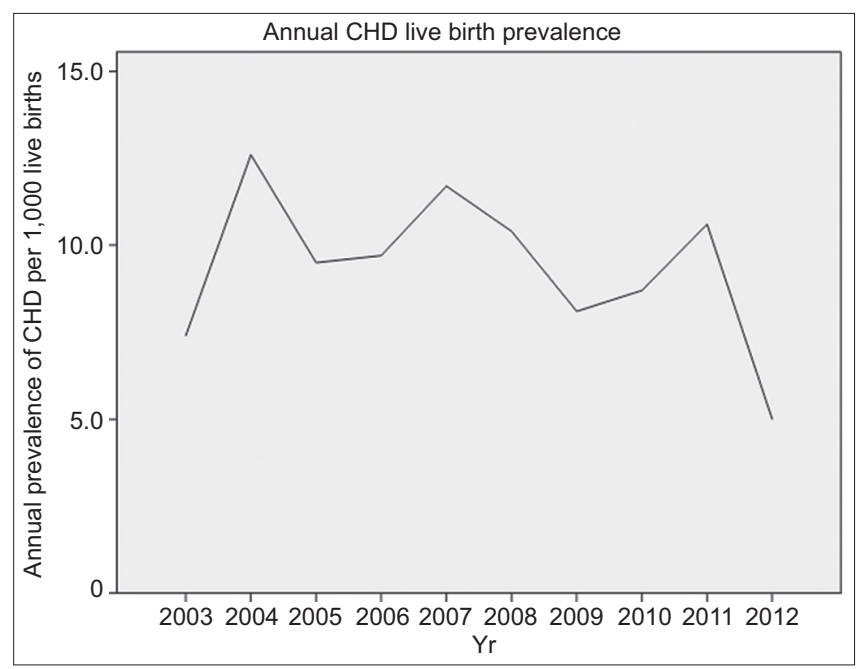

Fig. 2 Line graph shows the annual prevalence of live births with congenital heart disease (CHD) over a ten-year period.

$29(18.7 \%)$ were considered small for gestational age and 9 (5.8\%) were considered large for gestational age. Mean $( \pm$ SD) maternal age at delivery was $31.0 \pm 5.7$ years. The median (range) Apgar scores at one minute and five minutes were 8 (3-9) and 9 (5-10), respectively. Of the 155 cases, 85 (54.8\%) were female and most $(92.3 \%)$ did not have a positive family history of CHD.

The chief presentation that prompted cardiology referral for the 108 inpatients was the presence of a murmur $(n=83,76.9 \%)$. Other signs such as tachypnoea $(\mathrm{n}=9,8.3 \%)$ and cyanosis $(\mathrm{n}=4,3.7 \%)$ were far less common. 10 (9.3\%) asymptomatic babies were referred because of abnormal antenatal imaging or following the diagnosis of a syndrome. Table I shows the types of CHD according to inpatient (SGH neonatal unit) and outpatient (KKH cardiology database) diagnoses. The commonest lesion found among inpatients was ventricular septal defect (54.8\%), followed by pulmonary stenosis $(17.4 \%)$. However, the $\mathrm{KKH}$ cardiology database showed that pulmonary stenosis (44.7\%) was the commonest $\mathrm{CHD}$ detected after discharge from the SGH neonatal unit, followed by ventricular septal defect (27.7\%). Of the cases diagnosed at $\mathrm{KKH}$ following discharge from $\mathrm{SGH}$, one case was a critical CHD in a four-day-old baby who presented at the $\mathrm{KKH}$ emergency department in a state of cardiovascular collapse and was eventually diagnosed with coarctation of the aorta.

Of the CHD live births, $94.8 \%(147 / 155)$ of the mothers had undergone prenatal ultrasonography; of these, $8.2 \%(12 / 147)$ received an antenatal diagnosis of CHD. An additional 25 mothers received a prenatal diagnosis of $\mathrm{CHD}$ and opted for pregnancy termination after counselling or having encountered intrauterine death. Only one of these 25 mothers had consented to postmortem examination of her fetus. In this case, although the prenatal imaging was suspicious for a ventricular septal defect, postmortem examination revealed a normal heart with features of Beare-Stevenson syndrome. Therefore, the overall antenatal detection rate of $\mathrm{CHD}$ was 36 (12 live births and 24 fetuses) out of 171 pregnancies (i.e. $21.1 \%$ ).

Table II compares the prenatal and postnatal diagnoses of seven selected critical CHD. Five of the 14 live-born cases of critical CHD were detected prenatally, and the diagnoses included atrioventricular septal defect, hypoplastic left heart syndrome and tetralogy of Fallot. Another 11 fetuses with prenatal diagnosis of critical CHD underwent termination, giving a critical CHD antenatal detection rate of $64.0 \%$ (16 out of 25 [14 live births and 11 fetuses]). The antenatal detection rate in the critical $\mathrm{CHD}$ group was three times that of the group as a whole (64.0\% vs. $21.1 \%)$.

Performance of a neonatal cardiac screen, comprising prenatal ultrasonography and clinical examination, was calculated separately for babies with any CHD and those with any one of the seven critical CHD. The sensitivity and specificity of screening for any CHD was $64.5 \%$ and $99.7 \%$, respectively, while the false-negative and false-positive rates were $35.5 \%$ and $0.3 \%$, respectively. The positive and negative predictive values were $66.7 \%$ and $99.6 \%$, respectively. The positive and negative likelihood ratios were 215 and 0.36 , respectively. Likewise, sensitivity and specificity of screening for critical CHD was $92.9 \%$ and $99.1 \%$, respectively, while the false-negative and false-positive rates were $7.1 \%$ and $0.9 \%$, respectively. The positive predictive value was $8.9 \%$, while the negative predictive value was $100 \%$. The positive and negative likelihood ratios were 103 and 0.07 , respectively.

\section{DISCUSSION}

The present study showed that the incidence of CHD at birth at SGH was 9.7 per 1,000 live births, which appeared marginally higher than that reported in Victoria, Australia (7.8 per 1,000), ${ }_{1}^{(16)}$ Atlanta, United States (US; 8.1 per 1,000), ${ }^{(18)}$ and Europe (7.2 per 1,000$).{ }^{(19)}$ A likely explanation is the practically complete case ascertainment due to highly rigorous data verification and maintenance of registries at both SGH (Birth Defect Registry) and $\mathrm{KKH}$ (cardiology database). An alternative reason may be the preferential referral pattern of primary healthcare doctors to send patients to $\mathrm{KKH}$, the largest paediatric cardiac and cardiothoracic service in Singapore. Interestingly, there was no significant change in CHD incidence over the ten-year study period.

It was not surprising that the antenatal detection rate was three times higher in the critical CHD group as compared to the group as a whole. Our antenatal detection rate of any CHD (21.1\%) compared favourably with that of a study from 
Table I. Types of CHD classified by the ICD-9-BPA classification system for inpatients $(n=108)$ and outpatients $(n=47)$.

\begin{tabular}{|c|c|c|c|c|}
\hline \multirow{2}{*}{$\begin{array}{l}\text { ICD-9 BPA } \\
\text { classification }\end{array}$} & \multirow[t]{2}{*}{ Type of CHD } & \multicolumn{3}{|c|}{ No. (\%) } \\
\hline & & Inpatient diagnosis $(n=108)$ & Outpatient diagnosis $(n=47)$ & Total $(n=155)$ \\
\hline 745.10 & Transposition of the great arteries & $1(0.9)$ & - & $1(0.6)$ \\
\hline 745.20 & Tetralogy of Fallot & $4(3.7)$ & - & $4(2.6)$ \\
\hline 745.40 & Ventricular septal defect & $72(66.7)$ & $13(27.7)$ & $85(54.8)$ \\
\hline 745.69 & Atrioventricular septal defect & $3(2.8)$ & - & $3(1.9)$ \\
\hline 745.90 & Unspecified defect of septal closure & - & $1(2.1)$ & $1(0.6)$ \\
\hline 746.00 & Pulmonary valve anomaly, unspecified & $1(0.9)$ & $1(2.1)$ & $2(1.3)$ \\
\hline 746.01 & Pulmonary atresia & $1(0.9)$ & - & $1(0.6)$ \\
\hline 746.02 & Pulmonary stenosis & $6(5.6)$ & $21(44.7)$ & $27(17.4)$ \\
\hline 746.09 & Other pulmonary valve defects & $1(0.9)$ & - & $1(0.6)$ \\
\hline 746.30 & Congenital stenosis of aortic valve & - & $1(2.1)$ & $1(0.6)$ \\
\hline 746.60 & Congenital mitral insufficiency & - & $1(2.1)$ & $1(0.6)$ \\
\hline 746.70 & Hypoplastic left heart syndrome & $1(0.9)$ & - & $1(0.6)$ \\
\hline 746.87 & Dextrocardia & $4(3.7)$ & - & $4(2.6)$ \\
\hline 746.90 & Unspecified anomaly of heart & $6(5.6)$ & $5(10.6)$ & $11(7.1)$ \\
\hline 747.10 & Coarctation of the aorta & $2(1.9)$ & $1(2.1)$ & $3(1.9)$ \\
\hline 747.21 & Anomalies of aortic arch & $1(0.9)$ & - & $1(0.6)$ \\
\hline 747.30 & Anomalies of pulmonary artery & $2(1.9)$ & $2(4.3)$ & $4(2.6)$ \\
\hline 747.41 & $\begin{array}{l}\text { Total anomalous pulmonary venous } \\
\text { drainage }\end{array}$ & $1(0.9)$ & - & $1(0.6)$ \\
\hline 747.49 & Other anomalies of great veins & $1(0.9)$ & - & $1(0.6)$ \\
\hline 747.90 & $\begin{array}{l}\text { Unspecified anomaly of circulatory } \\
\text { system }\end{array}$ & $1(0.9)$ & - & $2(1.3)$ \\
\hline
\end{tabular}

BPA: British Paediatric Association; CHD: congenital heart disease; ICD-9: International Classification of Diseases Ninth Revision

TABLE II. Comparison of antenatal detection with postnatal echocardiography among seven selected critical CHD.

\begin{tabular}{|c|c|c|c|c|c|c|}
\hline \multirow{2}{*}{$\begin{array}{l}\text { ICD-9 BPA } \\
\text { classification }\end{array}$} & \multirow[t]{2}{*}{ Type of CHD } & \multicolumn{5}{|c|}{ No. (\%) } \\
\hline & & $\begin{array}{l}\text { Live } \\
\text { births } \\
(n=14)\end{array}$ & $\begin{array}{l}\text { Live births } \\
\text { with antenatal } \\
\text { diagnosis }(n=5)\end{array}$ & $\begin{array}{l}\text { Terminated } \\
\text { fetuses } \\
(\mathbf{n}=11)\end{array}$ & $\begin{array}{l}\text { Live births \& } \\
\text { terminated } \\
\text { fetuses }(n=25)\end{array}$ & $\begin{array}{l}\text { True antenatal } \\
\text { diagnosis }(n=16)\end{array}$ \\
\hline 746.70 & Hypoplastic left heart syndrome & 1 & $1 / 1(100.0)$ & 3 & 4 & 4/4 (100.0) \\
\hline 745.10 & Transposition of the great arteries & 1 & $0 / 1(0)$ & 1 & 2 & $1 / 2(50.0)$ \\
\hline 747.10 & Coarctation of the aorta & 3 & $0 / 3(0)$ & 2 & 5 & $2 / 5(40.0)$ \\
\hline 745.20 & Tetralogy of Fallot & 4 & $2 / 4(50.0)$ & 2 & 6 & $4 / 6(66.7)$ \\
\hline 745.69 & AVSD & 3 & $2 / 3(66.7)$ & 2 & 5 & $4 / 5(80.0)$ \\
\hline 746.01 & Pulmonary atresia & 1 & $0 / 1(0)$ & 1 & 2 & $1 / 2(50.0)$ \\
\hline 747.41 & TAPVD & 1 & $0 / 1(0)$ & 0 & 1 & $0 / 1(0)$ \\
\hline
\end{tabular}

AVSD: atrioventricular septal defect; BPA: British Paediatric Association; CHD: congenital heart disease; ICD-9: International Classification of Diseases Ninth Revision; TAPVD: total anomalous pulmonary venous drainage

the Czech Republic, ${ }^{(20)}$ which reported an antenatal detection rate of $28.5 \%$. Our antenatal detection rate of critical CHD $(64.0 \%)$ was in keeping with the range reported in recent years from Utah, USA (39\%), ${ }^{(21)}$ the United Kingdom (UK; 35\%), ${ }^{(22)}$ Australia (53\%)(16) and the Czech Republic (80.7\%). ${ }^{(20)}$ Several factors affect the detection rate of an antenatal screening programme, including the operator's experience, the specific view employed (four-chamber vs. extended examination), as well as the timing and frequency of ultrasonography, which depends on centre-based protocols. ${ }^{(23)}$ Thus, it is challenging to do a direct comparison of antenatal detection rates among different centres. ${ }^{(23)}$
A wide difference was found in the antenatal detection rate for individual critical CHD. Prenatal detection of hypoplastic left heart syndrome, atrioventricular septal defect and tetralogy of Fallot was generally high at $100.0 \%, 66.7 \%$ and $50.0 \%$, respectively. However, at least half of the cases of transposition of the great arteries, coarctation of the aorta, pulmonary atresia, and the single case of total anomalous pulmonary venous drainage were not detected - a finding that was highly similar to the experience reported elsewhere. ${ }^{(10,11,16)}$

In 81 mothers who underwent routine prenatal sonograms and delivered babies with isolated ventricular septal defect, only $1(1.2 \%)$ had received the diagnosis prenatally (data not shown). 
Areas of hypoechogenicity in the four-chamber view present inherent difficulty in diagnosing the exact size and location of an isolated ventricular septal defect. ${ }^{(24)}$ As the septum does not lie in a single plane, it can be difficult to assess the size of the defect in the ventricular septum. True ventricular septal defect is confirmed only when it is visible in at least two different planes. Newer studies have shown greatly improved prenatal detection rates of ventricular septal defect, especially for small isolated defects. ${ }^{(25,26)}$

Overall, the sensitivity of our cardiac screening programme, comprising prenatal ultrasonography and postnatal clinical examination without pulse oximetry screening, was fairly good - $64.5 \%$ for all CHD and $92.9 \%$ for selected critical CHD. This contrasts with the low screening sensitivity for all $\mathrm{CHD}$ reported in an eight-year UK study (18\%; 191 of 1,067 babies). ${ }^{(27)}$ When comparing critical CHD, our screening sensitivity was similar to that in a nine-year Swedish study, which reported an overall sensitivity of $80 \%$ between 1993 to $2001,{ }^{(28)}$ and in a two-year German study involving 34 institutions, which also showed a sensitivity of $80 \%$ using prenatal ultrasonography and postnatal physical examination. ${ }^{(29)}$

All but one of the 14 patients with critical CHD were diagnosed before discharge from $\mathrm{SGH}$. The only critical $\mathrm{CHD}$ undetected before discharge was coarctation of the aorta. In this case, the neonate was discharged from SGH as apparently 'healthy', but presented to $\mathrm{KKH}$ at Day 4 of life in a critical haemodynamic state. This baby was diagnosed through echocardiography to have severe juxta-ductal coarctation with subaortic ventricular septal defect, presumably after the ductus had closed. It is well known that coarctation of the aorta is very difficult to detect in the first days of life, primarily due to persistent ductal patency ${ }^{(30-33)}$ and relatively high pulmonary resistance.

The high positive likelihood ratios indicate that in the presence of sufficient risk factors for CHD in the patient (i.e. if pre-test probability is sufficiently high), a positive test results effectively confirms the presence of CHD. The significantly low negative likelihood ratio for critical CHD (0.07) meant that in cases where prior suspicion is low - as in most cases during screening - a negative result would virtually rule out critical CHD.

The present study has several important strengths. Firstly, highly rigorous cross-checking of data across multiple sources prevented double counting and reduced ascertainment bias. Secondly, all CHD were classified in a standard manner using the well-accepted ICD-9-BPA system. Thirdly, measurement bias was minimised, since echocardiography was undertaken by a relatively small number of paediatric cardiologists over the entire ten-year study period.

A possible limitation of our study was the lack of data on apparently healthy babies who may have been diagnosed with CHD in hospitals elsewhere. Furthermore, we did not examine the autopsy records of infants who may have had sudden unexpected death from cardiac causes. It is noteworthy that the critical CHD group was heterogeneous and consisted of very different malformations that have in common the risk of cardiac decompensation, even though the specific CHD that was regarded as 'critical' varies between centres. We chose the seven critical CHD on the basis that they were likely to require surgery or catheter-based intervention in the first year of life. A Swedish study regarded all ductal-dependent lesions as critical; these included critical aortic stenosis and aortic coarctation, but excluded tetralogy of Fallot. ${ }^{(34)}$ In contrast, the American Academy of Pediatrics/American Heart Association statement used a broader definition consisting of all lesions that required surgery or catheter intervention in the first year of life. ${ }^{(12)}$ Our selection was similar to the seven lesions selected by the US Secretary's Advisory Committee on Heritable Disorders in Newborn and Children as the primary target for screening in the US, except the latter excluded aortic coarctation but included truncus arteriosus. ${ }^{(35)}$

In conclusion, the present study reported a CHD incidence of 9.7 per 1,000 live births. The commonest CHD was ventricular septal defect, followed by pulmonary stenosis. The antenatal detection rate was three times higher in the critical CHD group as compared to the group as a whole, with marked differences among individual CHD. The $64.5 \%$ sensitivity of CHD screening supports our hypothesis that a significant proportion continues to remain undetected despite prenatal ultrasonography and postnatal clinical examination. The remarkably high positive likelihood ratios indicate that in cases where pre-test probability is sufficiently high, a positive result on screening effectively confirms the presence of CHD. The significantly low negative likelihood ratio for critical CHDs implies that in cases where prior suspicion for $\mathrm{CHD}$ is low, as in most cases during screening, a negative result would virtually rule out critical CHD. Further studies are needed to determine the extent to which incorporation of pulse oximetry screening would improve earlier detection of critical $\mathrm{CHD}$, and thereby reduce the mortality and morbidity associated with $\mathrm{CHD}$ among newly born babies.

\section{REFERENCES}

1. Kurinczuk JJ, Hollowell J, Boyd PA, et al. Inequalities in infant mortality project briefing paper 4 . The contribution of congenital anomalies to infant mortality. Oxford: National Perinatal Epidemiology Unit, 2010. Available at: https:// www.npeu.ox.ac.uk/downloads/files/infant-mortality/Infant-Mortality-BriefingPaper-4.pdf. Accessed July 10, 2018.

2. Centers for Disease Control and Prevention (CDC). Racial differences by gestational age in neonatal deaths attributable to congenital heart defects -- United States, 2003-2006. MMWR Morb Mortal Wkly Rep 2010; 59:1208-11.

3. Moon-Grady AJ, Morris SA, Belfort $\mathrm{M}$, et al. International Fetal Cardiac Intervention Registry: a worldwide collaborative description and preliminary outcomes. J Am Coll Cardiol 2015; 66:388-99.

4. Eapen RS, Rowland DG, Franklin WH. Effect of prenatal diagnosis of critical left heart obstruction on perinatal morbidity and mortality. Am J Perinatol 1998; 15:237-42.

5. Brown KL, Ridout DA, Hoskote A, et al. Delayed diagnosis of congenital heart disease worsens preoperative condition and outcome of surgery in neonates. Heart 2006; 92:1298-302.

6. Brown JW, Park HJ, Turrentine MW. Arterial switch operation: factors impacting survival in the current era. Ann Thorac Surg 2001; 71:1978-84.

7. Franklin O, Burch M, Manning N, et al. Prenatal diagnosis of coarctation of the aorta improves survival and reduces morbidity. Heart 2002; 87:67-9.

8. Tworetzky W, McElhinney DB, Reddy VM, et al. Improved surgical outcome after fetal diagnosis of hypoplastic left heart syndrome. Circulation 2001; 103:1269-73.

9. Knowles R, Griebsch I, Dezateux C, et al. Newborn screening for congenital heart defects: a systematic review and cost-effectiveness analysis. Health Technol Assess 2005; 9:1-152, iii-iv. 
10. Sharland G. Foetal cardiac screening and variation in prenatal detection rates of congenital heart disease: why bother with screening at all? Future Cardiol 2012; 8:189-202.

11. Simpsom JM, Jones A, Callaghan N, Sharland GK. Accuracy and limitations of transabdominal fetal echocardiography at 12-15 weeks of gestation in a population at high risk for congenital heart disease. BJOG 2000; 107:1492-7.

12. Mahle WT, Newburger JW, Matherne GP, et al. Role of pulse oximetry in examining newborns for congenital heart disease: a scientific statement from the AHA and AAP. Pediatrics 2009; 124:823-36.

13. Yip WY, Abdul Alim AH, Rajadurai VS. Pulse oximetry screening for critical congenital heart diseases: the current status. Perinatology 2017; 17;139-46.

14. British Paediatric Association Classification of Diseases, (successor to the Cardiff Diagnostic Classification): a Paediatric Supplement Compatible With the Ninth Revision of the WHO International Classification of Diseases, 1977. London: British Paediatric Association, 1979.

15. Fenton TR, Kim JH. A systematic review and meta-analysis to revise the Fenton growth chart for preterm infants. BMC Paediatr 2013; 13:59.

16. Chew C, Halliday JL, Riley MM, Penny DJ. Population-based study of antenatal detection of congenital heart disease by ultrasound examination. Ultrasound Obstet Gynecol 2007; 29:619-24.

17. Jaeschke R, Guyatt GH, Sackett DL. Users' guides to the medical literature. III. How to use an article about a diagnostic test. B. What are the results and will they help me in caring for my patients? The Evidence-Based Medicine Working Group. JAMA 1994; 271:703-7.

18. Reller MD, Strickland MJ, Riehle-Colarusso T, Mahle WT, Correa A. Prevalence of congenital heart defects in metropolitan Atlanta, 1998-2005. J Pediatr 2008; 153:807-13.

19. Dolk H, Loane M, Garne E; European Surveillance of Congenital Anomalies (EUROCAT) Working Group. Congenital heart defects in Europe: prevalence and perinatal mortality, 2000 to 2005. Circulation 2011; 123:841-9.

20. Marek J, Tomek V, Skovránek J, Povysilová V, Samánek M. Prenatal ultrasound screening of congenital heart disease in an unselected national population: a 21-year experience. Heart 2011; 97:124-30.

21. Secretary's Advisory Committee on Heritable Disorders in Newborns and Children. 2013 Annual Report. Available at: https://www.hrsa.gov/sites/default/ files/hrsa/advisory-committees/heritable-disorders/reports-recommendations/ reports/2013-annual-report.pdf. Accessed July 10, 2018

22. NICOR: National Institute for Cardiovascular Outcomes Research. National congenital heart disease audit website. Available at: https://nicor4.nicor.org. uk/CHD/an_paeds.nsf/vwContent/Antenatal\%20Diagnosis?Opendocument. Accessed July 10, 2018.

23. Chaoui R. The four-chamber view: four reasons why it seems to fail in screening for cardiac abnormalities and suggestions to improve detection rate. Ultrasound Obstet Gynecol 2003; 22:3-10.

24. Sharland G. Cardiac abnormalities associated with an abnormal four chamber view. BMUS Bull 2002; 10:11-6.

25. International Society of Ultrasound in Obstetrics and Gynecology, Carvalho JS, Allan LD, et al. ISUOG Practice Guidelines (updated): sonographic screening examination of the fetal heart. Ultrasound Obstet Gynecol 2013; 41:348-59.

26. International Society of Ultrasound in Obstetrics and Gynecology. Cardiac screening examination of the fetus: guidelines for performing the 'basic' and 'extended basic' cardiac scan. Ultrasound Obstet Gynecol 2006; 27:107-13.

27. Wren C, Richmond S, Donaldson L. Presentation of congenital heart disease in infancy: implications for routine examination. Arch Dis Child Fetal Neonatal Ed 1999; 80:F49-53.

28. Chang RK, Gurvitz M, Rodriguez S. Missed diagnosis of critical congenital heart disease. Arch Pediatr Adolesc Med 2008; 162:969-74.

29. Riede FT, Wörner C, Dähnert I, et al. Effectiveness of neonatal pulse oximetry screening for detection of critical congenital heart disease in daily clinical routine--results from a prospective multicenter study. Eur J Pediatr 2010; 169:975-81.

30. Ing FF, Starc TJ, Griffiths SP, Gersony WM. Early diagnosis of coarctation of the aorta in children: a continuing dilemma. Pediatrics 1996; 98(3 Pt 1):378-82.

31. Ward KE, Pryor RW, Matson JR, et al. Delayed detection of coarctation in infancy: implications for timing of newborn follow-up. Pediatrics 1990; 86:972-6.

32. Head CE, Jowett VC, Sharland GK, Simpson JM. Timing of presentation and postnatal outcome of infants suspected of having coarctation of the aorta during fetal life. Heart 2005; 91:1070-4

33. Mellander M, Sunnegårdh J. Failure to diagnose critical heart malformations in newborns before discharge--an increasing problem? Acta Paediatr 2006; 95:407-13.

34. de-Wahl Granelli A, Wennergren M, Sandberg K, et al. Impact of pulse-oximetry screening on the detection of duct dependent congenital heart disease: a Swedish prospective screening study in 39,821 newborns. BMJ 2009; 338:a3037.

35. Kemper AR, Mahle WT, Martin GR, et al. Strategies for implementing screening for critical congenital heart disease. Pediatrics 2011; 128:e1259-67.

About the First Author
Dr Alvin Ngeow is a practising neonatologist at the Singapore General Hospital neonatal unit and has
dual accreditation in paediatric medicine and neonatology. He has multiple interests in the field of
neonatology, including screening of congenital heart defects, the use of smartphones to screen for
neonatal jaundice, as well as management of babies with complex congenital conditions, including
congenital pulmonary lymphangiectasia and aplasia cutis congenita.

